\title{
BMJ Effect of a school-based peer education OPen intervention on physical activity and sedentary behaviour in Chinese adolescents: a pilot study
}

\author{
Zhaohui Cui, ${ }^{1,2}$ Smita Shah, ${ }^{1,3}$ Lijing Yan, ${ }^{2,4}$ Yongping Pan, ${ }^{5}$ Aiyu Gao, ${ }^{5}$ \\ Xiaoyan Shi, ${ }^{5}$ Yangfeng Wu, ${ }^{2,6}$ Michael John Dibley ${ }^{1}$
}

To cite: Cui Z, Shah S, Yan L, et al. Effect of a school-based peer education intervention on physical activity and sedentary behaviour in Chinese adolescents: a pilot study. BMJ Open 2012;2: e000721. doi:10.1136/ bmjopen-2011-000721

- Prepublication history for this paper is available online. To view this file please visit the journal online (http://dx. doi.org/10.1136/

bmjopen-2011-000721)

Received 5 December 2011 Accepted 16 April 2012

This final article is available for use under the terms of the Creative Commons Attribution Non-Commercial 2.0 Licence; see http://bmjopen.bmj.com

For numbered affiliations see end of article.

Correspondence to Dr Zhaohui Cui; cuizhaohui2008@yahoo.com. cn

\section{ABSTRACT}

Objective: To evaluate the effect on physical activity and sedentary behaviour of a pilot school-based peer education programme in urban Beijing, China.

Design: 4 junior high schools were matched by school size and randomised to intervention $(n=346)$ and control group $(n=336)$.

Intervention: Trained peer leaders from grade 7 by research staff delivered weekly 40-min lessons to their classmates over four consecutive weeks. Students in control schools received no intervention.

Outcome measures: A validated 7-day youth physical activity questionnaire was used to evaluate physical activity and sedentary behaviours at baseline (September 2010), 3 months (December 2010) and 7 months (May 2011). Generalised linear mixed models were applied to evaluate the effect.

Results: There was a significant decrease in time in sedentary behaviour on weekdays, $20 \mathrm{~min} /$ day at 7 months $(p=0.020)$ reported by students in the intervention schools compared with control schools. This reduction was mainly due to a reduction of $14 \mathrm{~min} /$ day in computer usage on weekdays $(p=0.0009)$. There were no significant differences in time on other sedentary behaviours, including television and DVD, video game, extracurricular reading, writing, drawing and listening to music, passive commuting and sitting to talk. There was also no significant difference in time in moderate-to-vigorous physical activity between intervention and control group.

Conclusions: Peer education appears to be a promising intervention in reducing sedentary behaviours in adolescents in China. These results need confirmation in a larger study.

Clinical trial registration number: ACTRN12612000417886 at http://ANZCTR. org.au

\section{INTRODUCTION}

Adolescents in China have become increasingly sedentary with a decrease in physical activity $^{1}$ and an increase in sedentary behaviour $^{2}$ over the past decade, concurrently

\section{ARTICLE SUMMARY}

Article focus

- To evaluate the effect on physical activity and sedentary behaviour of a pilot school-based peer education programme in grade 7 students in urban Beijing, China.

Key messages

- Peer education is a promising intervention to reduce sedentary behaviours in adolescents.

Strengths and limitations of this study

- Our intervention is innovative because the peer education programme is theory-based and easy to run by following the peer leader's manual. Peer leaders are trained in a short period of time and then educate their classmates. These features ensure the programme minimally interrupt school activities, cost-effective and feasible for larger scale implementation.

- With only two schools in each arm, potential confounders may not have been balanced across treatment groups. Also, physical activity was not objectively measured.

with the rapid socioeconomic development, especially in urban areas. This tendency to increasing sedentariness may be associated with an array of health problems, including overweight and obesity ${ }^{3}{ }^{4}$ that can track into adults. ${ }^{5}$ The prevalence of overweight and obesity has increased from $3.6 \%$ to $9.1 \%$ in adolescents in China in the past decade. ${ }^{6}$ Therefore, there is an urgent need for costeffective interventions to increase physical activity and to reduce sedentary behaviour in adolescents when they are establishing long-term lifestyle patterns.

Peers are a key component of the social network of adolescents who are transiting from childhood to adulthood. During the transition, youth move away from dependence on the family, to closer ties with their peers who give them the social support they 
need, especially with their schoolmates. Peer education programmes offer a powerful approach to educate youth and change their health behaviours. ${ }^{7}$ There is growing support for the use of student peer leaders to disseminate health information and to serve as role models in schools. ${ }^{8}$ Health education programmes in drug and alcohol issues have successfully employed peer teaching as an intervention strategy and appear to have a greater effect on health behaviour than adult-led interventions. ${ }^{9-12}$ Recent studies have shown that peer education programmes can significantly improve a range of health behaviours, including increasing fruit intake and reducing the risk of eating disorders in primary school students. ${ }^{13}$

However, little is known about whether this premise holds for motivating junior high school students to increase physical activity and to reduce sedentary behaviour. In the USA, one study using a combined peerled and teacher-led education ${ }^{14}$ in a high school found favourable impacts on physical activity in girls but not in boys. This study was evaluated with an internal control of classes in the same school that did not receive the intervention. Another study in elementary school students implemented a peer education programme to prevent obesity. However, the effect on physical activity was not reported. ${ }^{15}$

Few studies have examined the effect of an intervention on physical activity in adolescents in China. Only one study ${ }^{16}$ has been identified in two recent systematic reviews of studies of school-based and community-based prevention of childhood obesity in China ${ }^{17} 18$ with a physical activity intervention. This study implemented a teacher-led organised physical activity but did not report its effects on physical activity and sedentary behaviour. In China, peer education has been effective in promoting knowledge, attitudes and intention to change behaviour in AIDS prevention. ${ }^{19}$ However, no studies have evaluated the effect of peer education on physical activity and sedentary behaviours. Therefore, we conducted a pilot study from September 2010 to May 2011 in four junior high schools in urban Beijing, China, to test the feasibility of a peer-led education programme in changing obesity-related behaviours. The present study aims to examine the effects of peer education on physical activity and sedentary behaviour.

\section{METHODS}

\section{Study design}

A convenience sample of two small-sized and two largesized junior high schools in Dongcheng District, Beijing, China, were selected by the Dongcheng District Institute for Student Healthcare from schools with more than 160 students in grade 7 . These schools were matched by school population size, and in each matched pair, one school was randomly allocated by research staff by throwing a coin to intervention or the control group. In the large-sized schools, four classes were randomly drawn to participate in the study. In the small schools, all classes participated in the study. Peer education was implemented in classrooms in the first 2 months in intervention schools. No intervention was implemented in the control schools during the study. Assessments were conducted at baseline (September 2010), 3 months (December 2010) and 7 months (April/May 2011).

Survey protocols, instruments and processes for obtaining informed consent for this study were approved by institutional review committees of the University of Sydney, Sydney, Australia, and the Peking University Health Science Center, Beijing, China. The study was retrospectively registered because we were unaware of the International Committee of Medical Journal Editors's trial registration policy to include pilot studies.

\section{Start-up of the study}

Before the baseline assessment, a start-up conference was conducted with the attendance of officers from the Dongcheng District Institute for Student Healthcare, school principals and doctors, and research staff. The research plan and the responsibilities of participating institutions were introduced and discussed. The principal and participant information and consent forms were distributed to attendees from schools. After that, the principal and the school doctor in each intervention school held a meeting with all class teachers in participating classes in grade 7 to explain the research plan and to develop the school's work plan.

The information and consent forms were distributed to students in participating classes by class teachers in the four schools. Consent forms signed by both students and one of their guardians were collected before the baseline data collection. Only the students with consent forms signed by both themselves and their guardian were allowed to participate in the assessment. School consent forms signed by principals were collected as well.

\section{Intervention}

The four-component intervention was adapted, from a peer-led health promotion programme in Australia ${ }^{20}$ that was based on social cognitive theory ${ }^{21}$ and an empowerment educational approach, ${ }^{22}$ to ensure that it was culturally appropriate for Chinese students and fitted with our research objectives. The key modification was that peer leaders from grade 7 were selected to educate students in their own grade 7 instead of recruiting older peer leaders from grade 10 . This change was made because junior and senior high school are separate schools in China, and grade 9 children were too busy with examinations for entrance to senior high school to act as peer leaders. In addition, the component to increase awareness about local healthcare services was replaced by that to reduce consumption of carbonated drinks.

Therefore, our intervention covered four components: food choice, physical activity and sedentary behaviour, carbonated drinks and goal setting, which directly aimed at behaviour change. Learning activities were designed to be conducted in a variety of ways, including presentation, video watching, group discussion, games, 
experiments, lifestyle practice, skit playing and quiz show. Each component was designed to be taught at a 40min lesson. A peer leader's manual was developed to describe these structured activities.

To provide basic knowledge in healthy lifestyles and behavioural change and to encourage parents to support their children's behavioural changes, an eight-page pamphlet with knowledge supplemental to the four lessons was distributed to students and their parents in the intervention schools right after the baseline assessment.

Our intervention consisted of a three-step process, including peer leaders recruitment and training, peer-led education and student action.

\section{Peer leaders recruitment and training}

After the baseline assessment, four to eight peer leaders balanced by gender in each intervention class were selected by the class teacher from volunteer students based on their organisation and oral expression ability, influence among students and sense of responsibility.

Then, peer leaders in each intervention school were trained by research staff in three after-school 90-min workshops over three consecutive days at school. We explained and practiced all the four components, with the aim of enabling peer leaders to successfully deliver the lessons to their classmates. In the whole training process, peer leaders were encouraged to learn the skills as a peer leader to actively interact with peers and to facilitate interaction between peers.

\section{Peer education}

Before each peer education lesson, school doctors or class teachers had a meeting with peer leaders to clarify each peer leader's responsibility. Peer leaders prepared and practiced their lessons.

Peer leaders then delivered four 40-min peer education lessons to their classmates over four consecutive weeks in their classrooms, following the peer leader's manual. The four peer education activities were integrated into the existing health education courses and class meetings.

The students (29-42 students per class) sat either in one large or several small circles. Given the heavy academic pressure of peer leaders and to ensure feasibility, we used a different pair of peer leaders to deliver the lessons.

During the peer education, a school teacher was present to help maintain classroom order.

\section{Student action}

Students were encouraged to maintain a healthy lifestyle based on the personal goals set in the fourth peer education lesson. The peer leaders were encouraged to be role models and to facilitate other students to maintain healthy lifestyles.

\section{Assessment}

Physical activity

A validated 7-day youth physical activity questionnaire ${ }^{23}$ was modified to collect information on moderate-to- vigorous physical activity (MVPA) and sedentary behaviour in the previous week. Trained medical students, who were blinded to the assignment of the intervention, explained the questionnaire to students in the classroom. In the questionnaire, in-school and out-of-school MVPA were recorded with a 12-item and 18-item scale to collect information on days, frequency per day and duration per time, respectively. Commuting to and from school was recorded using a 4-item scale, including walking, cycling, public transportation and picking up by parents. For those who walk or cycle, frequency and time of travelling were collected separately by to and from school. For those who take public transportation (bus, subway and taxi), frequency and time of walking between public transportation station/stop and home (or school) were collected. Whether they were picked up from school by their guardians was also collected. Sedentary behaviour was assessed by an 8-item scale, including TV viewing, DVD and video tape viewing, computer usage for entertainment, electronically game playing, extracurricular reading, drawing/writing/listening to music, sitting to phone call or chat, and playing musical instruments on weekdays and weekends.

\section{Body mass index}

Height was measured to the nearest $0.1 \mathrm{~cm}$ without shoes with a portable stadiometer and weight in lightweight clothing was measured to the nearest $0.1 \mathrm{~kg}$ on a calibrated beam scale. Body mass index (BMI) was calculated as weight in kilograms/(height in metres) ${ }^{2}$. Overweight and obesity were defined using the ageand sex-specific BMI cut-offs recommended by the International Obesity Task Force. ${ }^{24}$

\section{Process evaluation and adverse events}

Process evaluation was conducted by direct observation and focus group discussion in each intervention school. Research staff (ZC) and an officer from Dongcheng District Institute for Student Healthcare observed the peer education classes in the two intervention schools. In addition, immediately after the intervention, two focus group discussions were conducted among peer leaders and their peers to obtain feedback about the programme in each intervention school. Stratified by participating class, 12 students were randomly invited to participate for each focus group discussion. The discussion chaired by a trained research staff was recorded. Also in-depth interviews were held with a principal, class teacher, school doctor and physical education teacher from each intervention school.

Adverse events (injury) related to the intervention were reported by the intervention schools to the Dongcheng District Institute for Student Healthcare.

\section{Statistical analysis}

Given that only two schools were included in each arm, the baseline characteristics in the two arms may not be comparable, although schools were matched. Thus, intention-to-treat analysis was not applied in the present 
analysis, and the students who were lost to follow-up $(6.2 \%)$ were excluded from the analysis. The baseline characteristics of students with all three measurements were compared with those of students who were lost to follow-up.

The effect of the intervention on physical activity was evaluated by the relative changes in time (or MET $\times$ time) for in-school and out-of-school MVPA, active commuting to and from school (walking or cycling) and total MVPA between intervention and control groups compared with baseline. The effect of the intervention on sedentary behaviour was evaluated by the relative changes in time in individual activities and the total activity.

Generalised linear mixed models was applied to obtain means by group and to evaluate the effect of the intervention on physical activity and sedentary behaviours at 3 and 7 months after adjustment for age, sex and BMI at baseline, with school, class ${ }^{25}$ and within-subject correlation as random effect and with a covariance structure of simple diagonal using SAS V.9.2 (SAS Institute). In the analysis to evaluate the effect of the intervention, the cluster effect of matched school pairs ${ }^{26}$ was also treated as random effect. In addition, two interaction terms (sex by group, and group by time points of data collection) were added to evaluate that whether intervention effect was modified by sex or time.

\section{RESULTS}

\section{Participants}

A total of 758 students were eligible for the study in the four schools (figure 1). Signed consent forms were obtained from 738 students $(97.4 \%)$. Nine students (1.2\%) missed the baseline assessment and 47 students $(6.2 \%)$ were lost to follow-up, which led to a total of 682 $(90.0 \%)$ participants with 336 in the control arm and 346 in the intervention arm available for the analysis. There were no significant differences in gender, age, weight status and mean BMI between students with all measurements and those lost to follow-up across research arms at baseline (data not shown).

Baseline characteristics between the control and intervention groups were compared separately in boys and girls as shown in table 1. For boys, mean BMI $(p=0.038)$ and prevalence of overweight and obesity

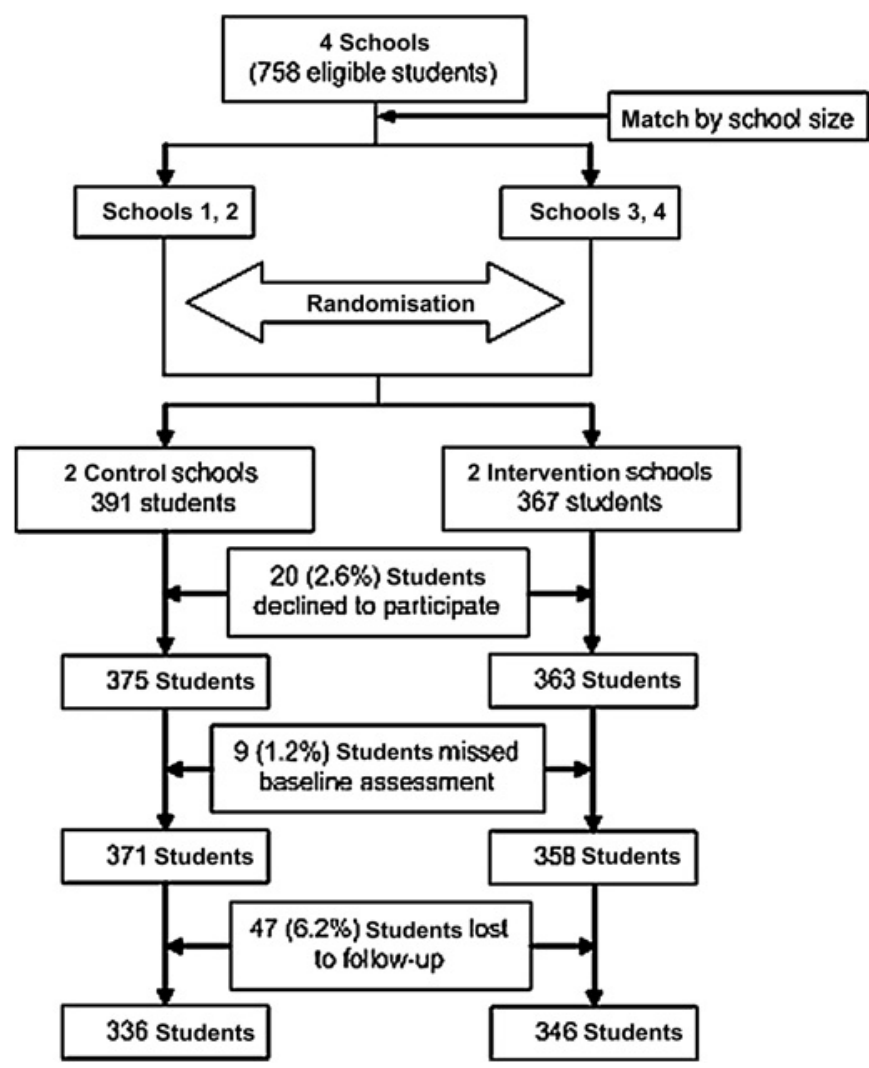

Figure 1 Flow of the participants through the trial.

$(p=0.016)$ were significantly lower in the control group than those in the intervention group. No significant differences were found in MVPA and sedentary behaviours between groups by gender at baseline as seen in tables 2 and 3.

\section{Adjusted effect on MVPA}

There was no significant difference between groups in time in total MVPA, in-school and out-of-school MVPA and active commuting to school at 3 and 7 months, after adjustment for age, gender, BMI at baseline (table 2).

\section{Adjusted effect on sedentary behaviours}

As shown in table 3, there was no significant difference between groups in time on sedentary behaviours at 3 months. At 7 months, time on computer usage on

\begin{tabular}{|c|c|c|c|c|}
\hline \multirow[b]{2}{*}{ Variable } & \multicolumn{2}{|l|}{ Intervention $\ddagger$} & \multicolumn{2}{|l|}{ Control $\neq$} \\
\hline & Boys $(n=176)$ & Girls $(n=170)$ & Boys $(n=177)$ & Girls $(n=159)$ \\
\hline Age, mean $\pm S D$, years & $12.7 \pm 0.5$ & $12.6 \pm 0.5$ & $12.8 \pm 0.5$ & $12.6 \pm 0.4$ \\
\hline \multicolumn{5}{|l|}{ Weight status, $\%$} \\
\hline Normal weight & 51.1 & 76.5 & $64.4^{*}$ & 76.7 \\
\hline Overweight & 34.1 & 17.6 & 25.4 & 15.7 \\
\hline Obesity & 14.8 & 5.9 & 10.2 & 7.5 \\
\hline BMI, $\mathrm{kg} / \mathrm{m}^{2}$ & $21.7 \pm 4.6$ & $20.2 \pm 3.8$ & $20.6 \pm 4.2^{\star}$ & $19.9 \pm 4.6$ \\
\hline
\end{tabular}


Table 2 Daily time and MET ${ }^{*} \times$ time on MVPA† at baseline $\neq, 3$ months and 7 months

\begin{tabular}{|c|c|c|c|c|c|c|c|c|c|}
\hline & \multirow[b]{2}{*}{ Sample (n) } & \multicolumn{2}{|c|}{ Baseline§ } & \multicolumn{2}{|c|}{3 months $\S$} & \multirow[b]{2}{*}{ p Valueq } & \multicolumn{2}{|c|}{7 months $\S$} & \multirow[b]{2}{*}{ p Valueq } \\
\hline & & Mean & SE & Mean & SE & & Mean & SE & \\
\hline \multicolumn{10}{|c|}{ Total MVPA, min/day } \\
\hline Control & 295 & 196.7 & 11.1 & 183.3 & 12.6 & & 171.3 & 11.4 & \\
\hline Intervention & 323 & 190.1 & 10.8 & 179.6 & 12.4 & 0.83 & 171.6 & 11.2 & 0.94 \\
\hline \multicolumn{10}{|c|}{ Total MVPA, MET $\times$ min/day } \\
\hline Control & 295 & 998.6 & 58.4 & 957.6 & 90.6 & & 874.3 & 73.8 & \\
\hline Intervention & 323 & 967.8 & 57.0 & 917.0 & 89.9 & 0.66 & 869.2 & 73.0 & 0.88 \\
\hline \multicolumn{10}{|c|}{ MVPA in school, min/day } \\
\hline Control & 321 & 95.6 & 4.8 & 105.5 & 8.7 & & 88.8 & 9.4 & \\
\hline Intervention & 337 & 92.6 & 4.7 & 99.2 & 8.7 & 0.52 & 92.8 & 9.3 & 0.77 \\
\hline \multicolumn{10}{|c|}{ MVPA in school, MET $\times$ min/day } \\
\hline Control & 321 & 513.9 & 26.0 & 593.2 & 67.6 & & 488.0 & 62.2 & \\
\hline Intervention & 337 & 498.9 & 25.4 & 533.2 & 67.4 & 0.38 & 497.8 & 61.9 & 0.99 \\
\hline \multicolumn{10}{|c|}{ MVPA out school, min/day } \\
\hline Control & 314 & 108.7 & 10.0 & 90.8 & 5.5 & & 89.5 & 7.8 & \\
\hline Intervention & 329 & 103.2 & 9.9 & 91.1 & 5.4 & 0.97 & 88.9 & 7.8 & 0.94 \\
\hline \multicolumn{10}{|c|}{ MVPA out school, MET $\times$ min/day } \\
\hline Control & 314 & 549.4 & 53.3 & 462.1 & 36.1 & & 449.4 & 38.7 & \\
\hline Intervention & 329 & 514.6 & 53.0 & 456.0 & 35.6 & 0.91 & 438.9 & 38.4 & 0.81 \\
\hline \multicolumn{10}{|c|}{ Active commuting to school, MET $\times$ min/day } \\
\hline Control & 320 & 131.6 & 13.1 & 115.1 & 17.2 & & 120.6 & 11.4 & \\
\hline Intervention & 341 & 135.4 & 13.0 & 118.5 & 17.2 & 0.82 & 116.4 & 11.3 & 0.79 \\
\hline \multicolumn{10}{|c|}{$\begin{array}{l}\text { *MET denotes } 1 \mathrm{kcal} \times \mathrm{kg} \text { body weight }{ }^{-1} \times \mathrm{h}^{-1} \text {. } \\
\text { †MVPA denotes moderate-to-vigorous physical activity, that is, activities with an MET } \geq 3 \text {. Total MVPA is the sum of in-school and out-of-schoo } \\
\text { MVPA and active commuting to school. } \\
\text { fComparison between control group and intervention group in each variable at baseline is not significant. } \\
\text { SDData were adjusted for age, gender and body mass index at baseline. } \\
\text { ๆComparison between intervention and control groups was adjusted for age, gender, body mass index at baseline, interaction between } \\
\text { measurement time and groups, and cluster effect in randomisation pair, school and class level, within-subject correlation using PROC GLIMMIX } \\
\text { procedure in SAS V.9.2. }\end{array}$} \\
\hline
\end{tabular}

weekdays in the intervention group was $15 \mathrm{~min} /$ day (data not shown) lower $(\mathrm{p}=0.0009)$ than that in control schools. As a result, the daily time for computer usage in the intervention group was significant lower than that in control group $(p=0.016)$. Also, there was a significant decrease in time in sedentary behaviour on weekdays, $20 \mathrm{~min} /$ day (data not shown) at 7 months $(\mathrm{p}=0.020)$ reported by students in the intervention schools compared with control schools. Time on total sedentary behaviours in intervention group was $22 \mathrm{~min} /$ day (data not shown) lower than that in control group, but the difference was not significant $(p=0.06)$. There were no significant differences between groups in time on other sedentary behaviours at 7 months.

\section{Comparison between peer leaders and other students}

Selected variables were selected to evaluate the differences in the effect of the peer education programme on peer leaders and other participating students in intervention schools (table 4 ). There were no significant differences between peer leaders and other students in time on MVPA, sedentary behaviours and computer usage at both 3 and 7 months. By comparing the magnitudes of adjusted mean time through baseline to 7 months, we found that time on MVPA decreased more among peer leaders than other students, while time on sedentary behaviours decreased in other students, while slightly increased in peer leaders.

\section{Process evaluation and adverse events}

Research staff and education officer observed that the delivery of the four lessons by the peer leaders followed the peer leader's manual. From the focus group discussions, we found that the peer leaders performed well according to their peers and were able to involve the students in the activities. The teachers and students demonstrated that the peer education programme is feasible and is acceptable because it is innovative, easy and includes a range of activities. No adverse events were reported during the intervention.

\section{DISCUSSION}

This pilot study based on 682 students in four schools (two intervention and two control schools) indicated that the adapted peer education programme from Australia was feasible and acceptable in schools in Beijing, and it showed potential for reducing sedentary behaviours in adolescents, especially computer time.

Our intervention was innovative for a number of reasons. First, the peer education programme was well designed, structured and easy to run by following the manual. The training of peer leaders was shorter compared with other peer education studies in China that had a 4-day to 4-week training, ${ }^{19} 27$ which is an attractive feature in reducing costs and increasing feasibility for larger scale implementation. 
Table 3 Daily minutes spent on sedentary behaviours* at baseline ${ }^{*}, 3$ months and 7 months $\neq$

\begin{tabular}{|c|c|c|c|c|c|c|c|c|}
\hline & \multicolumn{2}{|c|}{ Baseline§ } & \multicolumn{2}{|c|}{3 months $\S$} & \multirow[b]{2}{*}{ p Valueq } & \multicolumn{2}{|c|}{7 months $\S$} & \multirow[b]{2}{*}{ p Valueq } \\
\hline & Mean & SE & Mean & SE & & Mean & SE & \\
\hline \multicolumn{9}{|c|}{ Sedentary behaviours } \\
\hline Control & 256.3 & 26.5 & 256.8 & 25.4 & & 258.8 & 25.5 & \\
\hline Intervention & 248.7 & 26.5 & 237.2 & 25.4 & 0.21 & 229.0 & 25.5 & 0.060 \\
\hline \multicolumn{9}{|c|}{ Sedentary behaviours, on weekdays } \\
\hline Control & 197.7 & 24.8 & 188.4 & 26.6 & & 201.1 & 28.8 & \\
\hline Intervention & 181.3 & 24.8 & 172.2 & 26.6 & 0.21 & 169.8 & 28.8 & 0.02 \\
\hline \multicolumn{9}{|c|}{ Sedentary behaviours, on weekend } \\
\hline Control & 403.8 & 31.5 & 428.2 & 23.8 & & 405.1 & 19.9 & \\
\hline Intervention & 419.7 & 31.4 & 399.3 & 23.7 & 0.25 & 377.5 & 19.7 & 0.25 \\
\hline \multicolumn{9}{|l|}{ Computer } \\
\hline Control & 43.6 & 11.4 & 52.0 & 11.9 & & 59.2 & 11.0 & \\
\hline Intervention & 45.6 & 11.4 & 42.2 & 11.9 & 0.13 & 43.0 & 11.0 & 0.016 \\
\hline \multicolumn{9}{|c|}{ Computer, on weekdays } \\
\hline Control & 26.7 & 8.9 & 31.2 & 9.1 & & 39.7 & 8.8 & \\
\hline Intervention & 25.1 & 8.9 & 22.8 & 9.1 & 0.07 & 23.3 & 8.8 & 0.0009 \\
\hline \multicolumn{9}{|c|}{ Computer, on weekend } \\
\hline Control & 85.9 & 17.7 & 104.1 & 19.0 & & 107.7 & 16.7 & \\
\hline Intervention & 97.1 & 17.7 & 90.7 & 19.0 & 0.27 & 91.9 & 16.7 & 0.18 \\
\hline \multicolumn{9}{|c|}{ Television and DVD } \\
\hline Control & 70.7 & 12.5 & 72.2 & 9.5 & & 69.0 & 11.2 & \\
\hline Intervention & 65.6 & 12.5 & 60.9 & 9.5 & 0.13 & 65.1 & 11.2 & 0.56 \\
\hline \multicolumn{9}{|l|}{ Video game } \\
\hline Control & 6.0 & 1.3 & 10.3 & 1.8 & & 11.9 & 1.9 & \\
\hline Intervention & 7.8 & 1.2 & 7.6 & 1.8 & 0.26 & 8.5 & 1.9 & 0.21 \\
\hline \multicolumn{9}{|c|}{ Extracurricular reading, writing, drawing and listening to music } \\
\hline Control & 83.6 & 4.1 & 74.1 & 5.0 & & 79.4 & 4.8 & \\
\hline Intervention & 81.3 & 4.1 & 79.6 & 4.9 & 0.4 & 72.6 & 4.8 & 0.29 \\
\hline \multicolumn{9}{|c|}{ Passive commuting } \\
\hline Control & 31.6 & 2.6 & 27.8 & 2.7 & & 25.6 & 2.5 & \\
\hline Intervention & 27.4 & 2.6 & 32.4 & 2.6 & 0.22 & 29.3 & 2.5 & 0.32 \\
\hline \multicolumn{9}{|c|}{ Sitting and talking } \\
\hline Control & 22.3 & 3.0 & 21.4 & 1.8 & & 16.8 & 1.7 & \\
\hline Intervention & 24.2 & 2.9 & 17.0 & 1.8 & 0.16 & 14.2 & 1.6 & 0.34 \\
\hline \multicolumn{9}{|c|}{$\begin{array}{l}\text { *Information on daily time spent on sedentary behaviours was collected with an } 8 \text {-item scale by weekdays and weekend, including TV viewing; } \\
\text { DVD viewing; computer usage; playing video games; extracurricular reading; extracurricular writing, drawing and listening to music; being } \\
\text { a passenger in a bicycle, a subway, a bus or a car; sitting and talking (face-to-face or by phone). Total sedentary behaviours are the sum of the } 8 \\
\text { items. } \\
\text { +Comparison between control group and intervention group in each variable at baseline is not significant. } \\
\text { fSample size in control group is } 336 \text { and in intervention group is } 345 \text {. } \\
\text { \$Data were adjusted for age, gender and body mass index at baseline. } \\
\text { ฯComparison between intervention and control groups was adjusted for age, gender, body mass index at baseline, interaction between } \\
\text { measurement time and groups, and cluster effect in randomisation pair, school and class level, within-subject correlation using PROC GLIMMIX } \\
\text { procedure in SAS V.9.2. }\end{array}$} \\
\hline
\end{tabular}

Second, the peer education programme directly aimed at behaviour change. Our programme delivered health information by a variety of participatory activities to motivate students to be more active. Also, students actively interacted with each other and to find out the most realistic solutions to their barriers to engage in more physical activity.

Third, our programme results in minimal interruption to school activities. Peer leaders were the classmates of the peers they educated, which reduced interruption to the regular education programmes in the schools compared with programmes that used senior students as peer leaders. The use of senior students is complicated in China because the schools need to adjust their curriculum to make both peer leaders and their 'peers' available at specific times, especially when senior peer leaders come from senior high schools that are separate from junior high schools. The use of senior peer leaders has been driven by concerns about the ability of younger students to educate and influence their immediate peers. However, the Healthy Buddies programme indicated that younger peer educators (students in grades $4-7)$ are effective in delivering the messages to students in kindergarten through grade $3 .^{15}$ In addition, peer leaders from the same class stayed in contact longer with their peers in future school life, which may contribute to the sustainability of the intervention. The minimal interruption to school also featured by the shorter 
Table 4 Comparison of daily minutes spent on total MVPA* and selected sedentary behaviours $†$ between peer leaders and other students $\ddagger$

\begin{tabular}{|c|c|c|c|c|c|c|c|c|}
\hline & \multicolumn{2}{|c|}{ Baseline $\S$} & \multicolumn{2}{|c|}{3 months $\S$} & \multirow[b]{2}{*}{ p Valueq } & \multicolumn{2}{|c|}{7 months $\S$} & \multirow[b]{2}{*}{ p Valueq } \\
\hline & Mean & SE & Mean & SE & & Mean & SE & \\
\hline \multicolumn{9}{|c|}{ Total MVPA, min/day } \\
\hline Peers & 195.7 & 10.0 & 181.4 & 9.0 & & 173.1 & 17.4 & \\
\hline Peer leaders & 192.1 & 18.3 & 197.9 & 17.5 & 0.42 & 182.5 & 21.9 & 0.50 \\
\hline \multicolumn{9}{|c|}{ Sedentary behaviours } \\
\hline Peers & 256.9 & 24.9 & 241.1 & 11.8 & & 234.5 & 15.2 & \\
\hline Peer leaders & 210.4 & 30.8 & 231.2 & 21.5 & 0.75 & 217.1 & 22.7 & 0.46 \\
\hline \multicolumn{9}{|c|}{ Sedentary behaviours, on weekdays } \\
\hline Peers & 188.7 & 24.9 & 174.8 & 15.2 & & 174.6 & 20.4 & \\
\hline Peer leaders & 145.1 & 30.3 & 167.7 & 22.6 & 0.80 & 157.5 & 25.6 & 0.41 \\
\hline \multicolumn{9}{|c|}{ Sedentary behaviours, on weekend } \\
\hline Peers & 429.7 & 24.9 & 402.8 & 17.2 & & 383.1 & 16.8 & \\
\hline Peer leaders & 373.6 & 39.2 & 388.4 & 35.9 & 0.75 & 364.5 & 32.0 & 0.65 \\
\hline \multicolumn{9}{|l|}{ Computer } \\
\hline Peers & 47.6 & 12.4 & 42.8 & 5.7 & & 45.6 & 4.1 & \\
\hline Peer leaders & 34.7 & 13.9 & 41.6 & 7.9 & 0.97 & 36.0 & 6.6 & 0.20 \\
\hline \multicolumn{9}{|c|}{ Computer, on weekdays } \\
\hline Peers & 26.6 & 9.8 & 23.4 & 4.8 & & 25.1 & 3.9 & \\
\hline Peer leaders & 16.5 & 11.2 & 21.4 & 6.7 & 0.82 & 18.8 & 6.0 & 0.34 \\
\hline \multicolumn{9}{|c|}{ Computer, on weekend } \\
\hline Peers & 100.5 & 19.1 & 91.4 & 7.9 & & 96.0 & 6.7 & \\
\hline Peer leaders & 80.1 & 22.7 & 92.1 & 13.8 & 0.86 & 78.2 & 12.8 & 0.23 \\
\hline \multicolumn{9}{|c|}{$\begin{array}{l}\text { *MVPA denotes moderate-to-vigorous physical activity, that is, activities with an MET } \geq 3 \text {. Total MVPA is the sum of in-school and out-of-schoo } \\
\text { MVPA and active commuting to school. } \\
\text { tInformation on daily time spent on sedentary behaviours was collected with an } 8 \text {-item scale by weekdays and weekend, including TV viewing } \\
\text { DVD viewing; computer usage; playing video games; extracurricular reading; extracurricular writing, drawing and listening to music; being } \\
\text { a passenger in a bicycle, a subway, a bus or a car; sitting and talking (face-to-face or by phone). Total sedentary behaviours are the sum of the } 8 \\
\text { items. } \\
\text { fNumber of peer leaders is } 59 \text { and of other students is } 286 \text {. } \\
\text { \$DData were adjusted for age, gender and body mass index at baseline. } \\
\text { ๆComparison between intervention and control groups was adjusted for age, gender, body mass index at baseline, interaction between } \\
\text { measurement time and groups, and cluster effect in school and class level, within-subject correlation using PROC GLIMMIX procedure in SAS } \\
\text { V.9.2. }\end{array}$} \\
\hline
\end{tabular}

training of peer leaders in our study. ${ }^{15}$ High school students in China have long school hours (5.4 days in school per week and 7.6 lessons $/$ day $^{28}$ ) and heavy pressure for academic achievement ( $2 \mathrm{~h} /$ day on homework $\left.^{28}\right)$; thus, minimal interruption to school is critical to ensure the sustainability of a school-based health promotion programme in this context.

Fourth, students were educated in groups regarded as small in China, which was associated with greater increases in knowledge, altered attitudes and intentions to change behaviour than those in larger groups in the peer education study ${ }^{19}$ because small groups facilitate cooperative learning, discussion and communication. ${ }^{29}$

Comparison with studies in China was limited because there has been only one study that used a teacher-led organised exercise to prevent obesity in adolescents, and physical activity outcome was not reported in this study. ${ }^{17}$ Limited studies have used peer education to promote physical activity in high-income countries. Consistent with our findings, Healthy Buddies, ${ }^{15}$ that used students in grade 4-7 trained by a teacher in a weekly 45-min lesson to promote physical activity in students from kindergarten to grade 3 over 21 weeks and reported no significant effects on physical activity. ${ }^{15}$ The possible explanation is the Sunny Sport Policy issued by the Department of Education in China. This programme has been implemented nationally and requires schools to ensure students have daily 1-h of physical activity in school. With this policy in place, it may be difficult for any school-based intervention to increase in-school nonorganised physical activity. Therefore, organised physical activity may potentially increase in-school physical activity in large cities in China, for example, to increase the intensity of physical education. For out-of-school physical activity, an intervention component at family and neighbourhood level involving environmental modification may be useful. Like Healthy Buddies, using teachers to train peer leaders may increase the feasibility of our programme to be implemented at a larger scale.

Several lessons have been learnt from our pilot study. First, future intervention studies should focus not only on TV viewing but also on emerging computer usage in large cities in China. The 2002 China National Nutrition and Health Survey reported $25 \%$ of adolescent used computers and spent an average of $1.2 \mathrm{~h} /$ day on the computer. $^{28}$ An average of 40-50 $\mathrm{min} /$ day of computer usage in our study suggests that computer usage accounted for a substantial amount of sedentary time in 
children in large cities in China. Furthermore, the decrease in sedentary time was mainly from the reduction in computer usage, which might partly be due to parental limits on the accessibility to computers for their children.

\section{CONCLUSIONS}

Our pilot study of a peer counselling intervention was promising in reducing sedentary behaviours in adolescents in China. These results need to be confirmed in a larger study.

Author affiliations

${ }^{1}$ Sydney School of Public Health, Sydney Medical School, University of Sydney, Sydney, Australia

${ }^{2}$ The George Institute for Global Health, Beijing, China

${ }^{3}$ Primary Health Care Education and Research Unit, Primary Care and Community Health Network, Sydney West Local Health District, Sydney, Australia

${ }^{4}$ Department of Preventive Medicine, Feinberg School of Medicine, Northwestern University, Chicago, Illinois, USA

${ }^{5}$ Dongcheng District Institute for Student Healthcare, Beijing, China

${ }^{6}$ Peking University Health Science Center, Beijing, China

Acknowledgements We are very grateful to the participating schools, children and their families. We thank the Australian Agency for International Development (AusAID) for funding Zhaohui Cui's doctoral scholarship in International Public Health at the University of Sydney, Australia, and this analysis, which is part of the requirements for his PhD studies. We also thank the National Institute of Nutrition and Food Safety, China Center for Disease Control and Prevention for the provision the physical activity questionnaire.

Contributors MJD, SS and ZC formulated the idea and study design. ZC modified the intervention materials, implemented the intervention, collected and cleaned the data, carried out the data analyses and drafted the manuscript. SS, LY, YW, YP, AG and MJD contributed to the implementation of the intervention. SS, LY and MJD contributed to the interpretations of the results. All authors contributed to revising the paper and approved the final version.

Funding This work was supported by the Nestle Foundation. The funders of the research had no role in the analysis nor the decision to publish.

Competing interests None.

Ethics approval Ethics approval was provided by the Peking University Biomedical Ethics Committee, China; Human Research Ethics Committee, the University of Sydney, Australia.

Provenance and peer review Not commissioned; externally peer reviewed.

Data sharing statement No additional data are available.

\section{REFERENCES}

1. Cui Z, Bauman A, Dibley MJ. Temporal trends and correlates of passive commuting to and from school in children from 9 provinces in China. Prev Med 2011;52:423-7.

2. Cui Z, Hardy LL, Dibley MJ, et al. Temporal trends and recent correlates in sedentary behaviours in Chinese children. Int J Behav Nutr Phys Act 2011;8:93.

3. Nelson MC, Gordon-Larsen P. Physical activity and sedentary behavior patterns are associated with selected adolescent health risk behaviors. Pediatrics 2006;117:1281-90.

4. Biddle SJ, Gorely T, Stensel DJ. Health-enhancing physical activity and sedentary behaviour in children and adolescents. J Sports Sci 2004;22:679-701.
5. Nicklas TA, von Duvillard SP, Berenson GS. Tracking of serum lipids and lipoproteins from childhood to dyslipidemia in adults: the Bogalusa Heart Study. Int J Sports Med 2002;23(Suppl 1):S39-43.

6. Cui Z, Huxley R, Wu Y, et al. Temporal trends in overweight and obesity of children and adolescents from nine Provinces in China from 1991-2006. Int J Pediatr Obes 2010:5:365-74.

7. Shah S, Peat J, Mazurski E, et al. Effect of peer led programme for asthma education in adolescents: cluster randomised controlled trial. BMJ 2001;322:583.

8. Klepp KI, Halper A, Perry CL. The efficacy of peer leaders in drug abuse prevention. J Sch Health 1986;56:407-11.

9. Holund U. Promoting change of adolescents' sugar consumption: the 'Learning by teaching' study. Health Educ Res 1990;5:451-8.

10. Perry CL, Grant M. Comparing peer-led to teacher-led youth alcohol education in four countries. Alcohol Health Res World 1988;12:322-6.

11. Orpinas $\mathrm{P}$, Parcel GS, McAlister A, et al. Violence prevention in middle schools: a pilot evaluation. J Adolesc Health 1995;17: 360-71.

12. Luepker RV, Johnson CA, Murray DM, et al. Prevention of cigarette smoking: three-year follow-up of an education program for youth. $J$ Behav Med 1983;6:53-62.

13. Cullen K, Baranowski T, Rittenberry L, et al. Child-reported family and peer influences on fruit, juice and vegetable consumption: reliability and validity of measures. Health Educ Res 2001;16:187-200.

14. Perry CL, Klepp K-I, Halper A, et al. Promoting healthy eating and physical activity patterns among adolescents: a pilot study of 'Slice of Life'. Health Educ Res 1987;2:93-103.

15. Stock S, Miranda C, Evans S, et al. Healthy Buddies: a novel, peerled health promotion program for the prevention of obesity and eating disorders in children in elementary school. Pediatrics 2007;120: e1059-68.

16. Zhang $Q$, Yue $Y$, Liu S, et al. Comprehensive intervention in children with simple obesity: two-year effect observation. Chin J Clin Rehab 2004;8:5084-6.

17. Li M, Li S, Baur LA, et al. A systematic review of school-based intervention studies for the prevention or reduction of excess weight among Chinese children and adolescents. Obes Rev 2008;9: 548-59.

18. Gao Y, Griffiths S, Chan EY. Community-based interventions to reduce overweight and obesity in China: a systematic review of the Chinese and English literature. J Public Health 2008;30:436-48.

19. Huang $\mathrm{H}, \mathrm{Ye} X$, Cai $\mathrm{Y}$, et al. Study on peer-led school-based HIV/ AIDS prevention among youths in a medium-sized city in China. Int $J$ STD AIDS 2008;19:342-6.

20. Shah S, Van der Sluijs CP, Lagleva M, et al. A partnership for health: working with schools to promote healthy lifestyle. Aust Fam Physician 2011;40:1-3.

21. Bandura A, ed. Social Foundations of Thought and Action: A Social Cognitive Theory. New Jersey: Prentice-Hall 1986.

22. Wallerstain N, Bernstain E. Empowerment education: Freire's ideas adapted to health education. Health Educ Q 1988;15:379-94.

23. Liu A, Ma G, Zhang Q, et al. Reliability and validity of a 7-day physica activity questionnaire for elementary students. Chin J Epidemiol 2003;24:901-4.

24. Cole TJ, Bellizzi MC, Flegal KM, et al. Establishing a standard definition for child overweight and obesity worldwide: international survey. BMJ 2000;320:1240-3.

25. West B, Welch K, Galecki A, eds. Linear Mixed Models: A Practical Guide Using Statistical Software. Boca Raton, FL: Chapman \& Hall/ CRC, 2007.

26. Foster GD, Sherman S, Borradaile KE, et al. A policy-based school intervention to prevent overweight and obesity. Pediatrics 2008;121 e794-802.

27. Shen LX, Hong $\mathrm{H}$, Cai $\mathrm{Y}$, et al. Effectiveness of peer education in HIV/STD prevention at different types of senior high schools in Shanghai, People's Republic of China. Int J STD AIDS 2008;19:761-7.

28. Ma G, Kong LZ, eds. Report on 2002 China National Nutrition and Health Survey (9): Behaviors and Lifestyles. Beijing: People's Medical Publishing House, 2006.

29. McLean DA. A model for HIV risk reduction and prevention among African American college students. J Am Coll Health 1994;42:220-3. 